\title{
Editorial
}

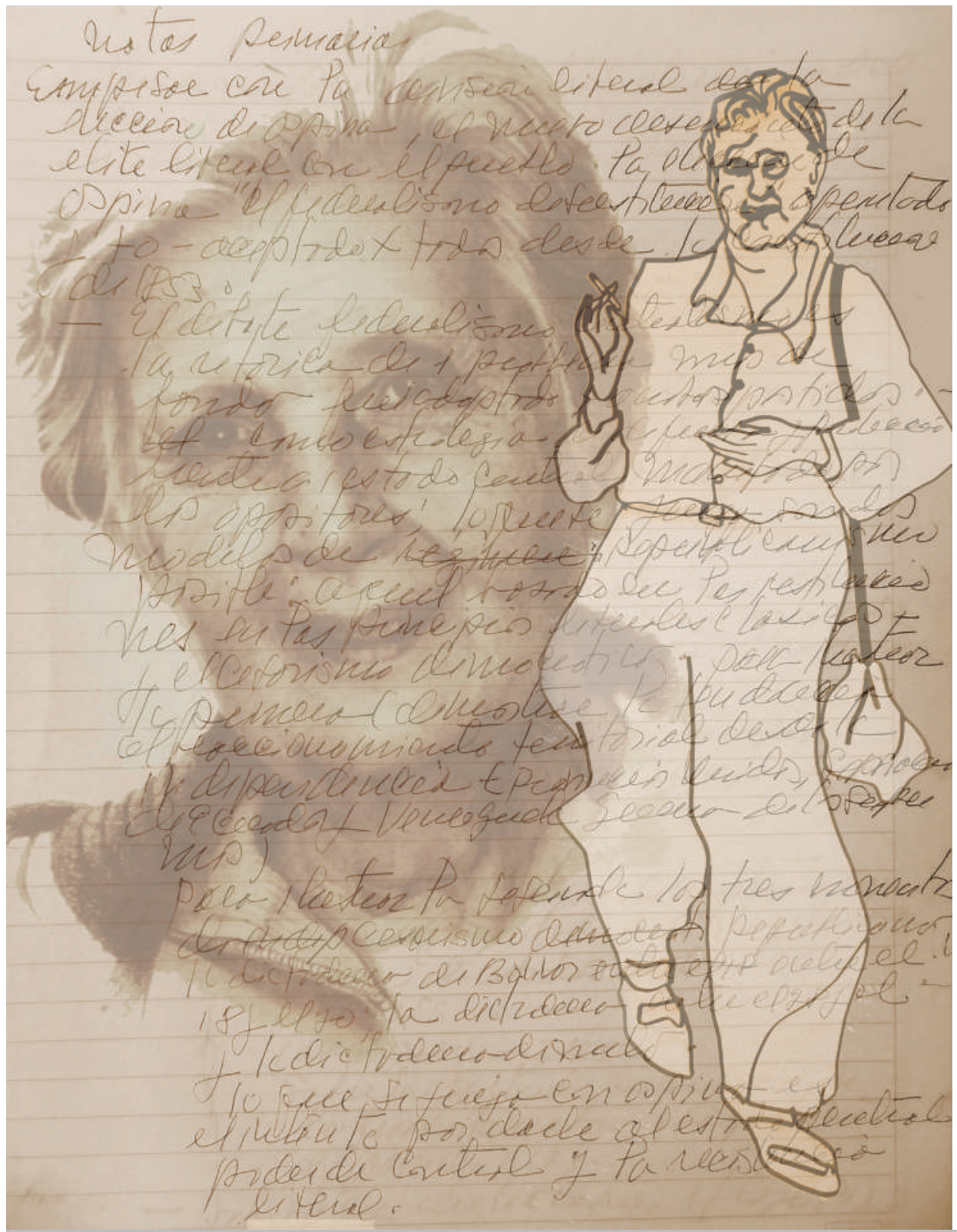

Collage a partir de: María Teresa Uribe de Hincapié de Martha Lucía Villafañe, dibujo en platina de hierro doblado y oxidado, 1,85 x 0,70 m, 2016. Obra donada por la familia Hincapié a la Universidad de Antioquia. Medellín, 8 de febrero de 2019. | María Teresa Uribe de Hincapié de G. Jaramillo. Dibujo donado por la familia Hincapié al Instituto de Estudios Políticos, Universidad de Antioquia. | Notas de clase de una libreta de apuntes de la maestra María Teresa Uribe de Hincapié. 


\section{Hasta siempre, maestra María Teresa Uribe de Hincapié}

La profesora María Teresa Uribe de Hincapié le cumplió a la muerte. En las primeras horas del primer día de 2019 decidió visitar la casa de este misterioso pero real personaje y enfrentarlo. Y lo hizo como lo han hecho en la historia los grandes hombres y mujeres: luego de recorrer un largo camino que duró casi 79 años y que la llevó por sinuosos senderos de goce y sufrimiento intelectual.

La Maestra, como le dicen todas aquellas personas que tuvieron la fortuna de compartir con ella en variados espacios, nos dejó una rica producción científica, mucha de ella publicada precisamente en la revista Estudios Políticos. En su trabajo indagativo abordó variados temas de las Ciencias Sociales: la violencia, la guerra, la configuración del Estado y el territorio, convirtiéndola en un referente obligado en la academia colombiana y latinoamericana.

La huella que dejó María Teresa en el Instituto de Estudios Políticos es imborrable. Además de ser una de las fundadoras del Instituto a finales de la década de 1980, participó como investigadora destacada y como docente comprometida en la Maestría de Ciencia Política. Además, se desempeñó entre 1996 y 2014 como miembro del Comité Editorial de la revista Estudios Políticos. En resumen, fue una líder académica irremplazable y que siempre recordaremos.

Precisamente, el 8 de febrero de 2019, las diversas unidades académicas de la Universidad de Antioquia en donde hizo presencia le rendimos un homenaje a La Maestra en el Teatro Universitario Camilo Torres, el mismo lugar donde cuatro años antes recibió el título Honoris Causa de Doctora en Ciencias Sociales (2015). En este acto, el director del Instituto de Estudios Políticos, William Fredy Pérez, quiso ofrecerle, en calidad de representante de un sin número de personas que allí nombra, unas sentidas palabras. A continuación, reproducimos ese discurso.

Germán Darío Valencia Agudelo (Colombia)*

\footnotetext{
* Director revista Estudios Políticos. Economista. Especialista en Gerencia Social. Magíster en Ciencia Política. Doctor en Estudios Políticos. Grupo Hegemonía, guerras y conflictos, Instituto de Estudios Políticos, Universidad de Antioquia UdeA. Calle 70 No. 52-21, Medellín, Colombia. Correo electrónico: german.valencia@udea.edu.co - Orcid: https://orcid.org/0000-0002-6412-6986
} 


\section{Buenas tardes.}

Los azares que me llevaron a conocerla han de ser los mismos que me pusieron aquí esta tarde. Porque hay tantas personas que podrían hablar en nuestro nombre: Clara Aramburo, Adriana González, Lucelly Villegas, Manuel Alonso, Ana María Jaramillo, Eumelia Galeano, Juan Carlos Vélez, Gloria Naranjo, Deicy Hurtado, Fabio Giraldo, William Restrepo...

En cualquier caso, soy portador de un saludo a la familia de María Teresa Uribe de Hincapié y de unas palabras de gratitud francamente sentidas en las facultades, escuelas e institutos del área de Ciencias Sociales, Humanidades y Artes, por sus decanos y decanas, directores y directoras, estudiantes, personas que desempeñan funciones administrativas, egresadas y egresados que entienden esto como un gesto necesario, como lo mínimo que públicamente deberíamos decir de ella, o como lo mínimo que públicamente deberíamos decirle a ella; y a Don Guillermo que la acompaña y a sus hijos Ana, Marta y Luis que nos hacen el honor de ocupar ahora un asiento en el Camilo.

La gente del Área sabe lo que siente y de lo que habla. Y lo sabe porque la oyó o la oye, la leyó y la lee. La vio y la ve cruzar los pasillos, ir entre edificios o trastear su oficina de bloque en bloque, así como la ven transgredir fronteras disciplinares, abrir portillos o romper cercos de esos con los cuales celosamente guardamos nuestras parcelas en este campo de las ciencias sociales, las humanidades y las artes. Ella iba por ahí juntando, como decía, «lo que las disciplinas académicas han fragmentado y separado». Esta gente del Área la supo fundando unidades o regentando algún departamento académico, animando organizaciones civiles, persistiendo en iniciativas no gubernamentales. La supo embarcada en comisiones que mediaban entre guerreros $y$, aun, participando de la planeación y ejecución de políticas públicas. Porque como sabe esta gente, aunque se ocupara de los campos de batalla, de la estrategia, de la barbarie, aunque se empeñara en disecar la criatura o la cibernética de la guerra o aunque su propia tranquilidad padeciera embates de feroces y poderosos aparatos, era difícil que ella personalmente construyera enemistades o que profesionalmente, por principio o como impostura, definiera contrincantes naturales

iCuánto le apasionó el conflicto social, y cuánto celebró la política! Pero cuánto le asombraron y dolieron los pleitos domésticos que se desataron o reeditaron invocando esencias nada más; pleitos que banalizaron la diversidad 
y la diferencia con la negación de los implicados; pleitos que, con el olvido del entorno, hicieron absurdo el desencuentro; o pleitos que prolongaron la hostilidad con la desmemoria de los triunfadores.

Esta gente del Área sabe que mucha otra gente de las ciencias sociales en el país y por fuera de él, casi, casi que nota primero que nosotros lo que ella estaba haciendo para entender los avatares de una democracia en construcción, para documentar las razones de los rufianes y el método de los vividores del conflicto, y para encontrar los materiales con los cuales procurarnos una ética pública; de lo que ella estaba haciendo para conocer el significado de los agravios inveterados y medir el impacto de las prácticas prolongadas de violencia sobre la cultura, las ciudadanías, la legitimidad y la soberanía, o sobre nuestra concepción de la ley, la patria, la autoridad, los imaginarios políticos; para localizar el trastrocamiento de las cosas públicas y las cosas privadas, la confusión de la popularidad con la legitimidad, del Estado con el gobierno, del gobierno con el partido y del partido con la urna, el cargo o el contrato; para ponderar la dimensión de la expulsión y del desplazamiento forzado; para hilar mecanismos de desigualdad, redes de poder, formas de configuración territorial y modelos de exclusión regional.

Esta gente del Área tiene visto que las huellas de María Teresa están en sus distritos, porque allí están sus afirmaciones teóricas, sus historias coherentes, sus maneras de aproximarse a un problema social o simplemente porque sus alumnas y sus alumnos están en Artes, Comunicaciones, Idiomas, Sociología, Historia, Derecho, Estudios Regionales, Estudios Políticos, Bibliotecología, Trabajo Social, Filosofía, Literatura, Educación, Economía... Que incluso hay unos extraordinarios infiltrados en las Ciencias de la Salud, en Exactas, en Ingeniería.

Por eso y por otras cosas que tantos amigos y tantas amigas han dicho y seguirán indicando, en el Área de Ciencias Sociales, Humanidades y Artes sentimos que lo mínimo que deberíamos hacer es decirle gracias... por tanto que nos da.

Muchas personas del Área confiesan, finalmente, que ya la desobedecieron por lo menos en una cosa: han derramado lágrimas. Y la profe no quería eso. Pero bueno, dicen también en el Área que persistirán por lo menos en un deseo que ella tenía: alcanzar de una maldita vez por todas ese momento en el cual «la guerra pierda sus contenidos heroicos y patrióticos y pase a ser vista como lo que es: el gran desastre humanitario». 
Usted, María Teresa, no se cansaba de recordarnos «que las palabras forman parte de la realidad». Así que entenderá, por lo que sea, que esto que mandan a decir del Área nos son «solo palabras».

Hasta siempre Maestra.

William Fredy Pérez Toro (Colombia)**

** Director del Instituto de Estudios Políticos, Universidad de Antioquia. Abogado. Magíster en Derecho Público. Magíster en Criminología y Ejecución Penal. Grupo Hegemonía, guerras y conflictos, Instituto de Estudios Políticos, Universidad de Antioquia UdeA. Calle 70 No. 52-21, Medellín, Colombia. Correo electrónico: william.perez@udea.edu.co - Orcid: https://orcid.org/00000003-1307-0692

Cómo citar este artículo: Valencia Agudelo, Germán Darío y Pérez Toro, William Fredy. (2019). Editorial. Hasta siempre, maestra María Teresa Uribe de Hincapié. Estudios Politicos (Universidad de Antioquia), 55, pp. 9-12. http://doi.org/10.17533/udea.espo.n55a01 